\title{
Britannia: violência, poder e contato
}

Tais Pagoto Bélo*

Resumo: Este artigo tem por intuito demonstrar - por meio de fontes escritas de autores antigos, como as obras de Tácito (Anais e $A$ vida de agrícola) e a de Dião Cássio (História de Roma) - como é descrita a violência da ocupação da província da Britannia, uma vez que a imposição do poder romano trouxe consequências para a vida da comunidade nativa dessa região. As rebeliões em destaque são a de Carataco e, principalmente, a de Boudica, dando maior ênfase na questão da violação das filhas da rainha dos iceni. Tal passagem corrobora os comentários acerca do ponto de vista de estudiosos da atualidade em relação a esse tema e a questão sobre o motivo pelo qual esses escritores da Antiguidade o apresentaram com tal veemência. As implicações do processo de invasão romana e a tomada da província vieram de resultados posteriores, que são demonstrados neste trabalho através da cultura material representada por epitáfios, pelos quais são conhecidas as vidas das mulheres nativas que se juntaram aos romanos, formando uma heterogeneidade cultural.

Palavras-chave: Britannia. Rebelião. Violência. Poder. Contato.

\section{Introdução}

Este estudo tem por objetivo demonstrar a violência da ocupação da província da Britannia pelos romanos e a reação contrária de rebeliões como a de Carataco e a de Boudica, no século I d.C., além de sua consequência, principalmente, para a população nativa feminina dessa região.

\footnotetext{
" Pós-doutoranda na Universidade Estadual de Campinas - UNICAMP e doutora pela mesma instituição. Essa pesquisa foi financiada pelo Conselho Nacional de Desenvolvimento Científico e Tecnológico - CNPq. E-mail: taispbelo@gmail.com.
} 
Na primeira parte deste trabalho, discute-se como os autores antigos, como Tácito, em Anais e $A$ vida de Agrícola, e Dião Cássio, em História de Roma, narram a empreitada do Império Romano contra o exército de Boudica. Além disso, observamos os pontos de vista de diferentes autores contemporâneos sobre o tema da guerra em si e, especialmente, da agressão feminina em momentos de hostilidade.

A segunda parte enfatiza exemplos da decorrência de ideias, diversidade, pluralidade e heterogeneidade cultural vista mediante os vestígios que indicam o estado das mulheres depois dos embates da conquista do território pelos romanos, utilizando-se de epitáfios.

Os dois principais tópicos que são conclamados aqui, as rebeliões e o contato, são temas escolhidos para questionamento. Geralmente, eles surgem interligados, levantando questões sobre eles próprios, bem como sobre o modo como são investigados atualmente e o contexto em que foram criados, manipulados e articulados pela administração imperial romana. Além disso, esses assuntos levam à reflexão acerca de como a população local respondeu a esses eventos. De acordo com Hingley (2010, p. 92),

Impérios dependem de negociação e de acordo para vir a existir e a sobreviver, mas outras estratégias, entre as quais a força e a violência, também desempenham um papel. Como Dick Whittaker argumentou, as duas posições, a de um estado romano intervencionista e a de uma população nativa pronta para responder, não agem, necessariamente, em oposição; intervenção e inovação diretas poderiam ocorrer uma ao lado da outra. As sociedades locais não se estabeleciam inteiramente como marginalizadas ou assimiladas, uma vez que tais categorias, na maioria dos casos, não estavam separadas, mas, ao contrário, sobrepunham-se.

As rebeliões caem por terra e entende-se que em cada província, assim como na Britannia, o império moldou-se aos compromissos regionais, mostrando uma variabilidade de grupos em um mundo global, com suas integrações e heterogeneidades, que se mantiveram por alguns séculos. 


\section{A província da Britannia}

A primeira investida romana contra os bretões da província da Britannia se deu por volta do ano 55 a.C., com Júlio César, que já tinha subjugado a Gália e agora levaria consigo Commio, rei dos atrebates, da Gália, o qual já tinha contato e conhecimento sobre a Britannia. Todavia, não foi dessa vez que os romanos adentraram nesse território, já que encontraram dificuldades para desembarcar na costa e o inverno estava próximo. Entretanto, César retornou à ilha no ano seguinte, 54 a.C., equipado com um número maior de legiões e cavalaria, e, assim, alcançou o vale do Tâmisa, onde futuramente seria Londinium (BÉLO, 2014, p. 52).

Cassivellauno, rei dos catuvellauni, foi subjugado com a ajuda da tribo vizinha, os trinovantes, que não se davam bem com esses primeiros. Desde então, os bretões começaram a pagar tributos aos romanos e a cumprir suas leis. A expedição de César abriu caminhos para o comércio com as tribos bretãs, o que inclui os iceni. Tempos depois, César acabou voltando para a Gália e escreveu sobre o que tinha encontrado na ilha (DAVIES; ROBINSON, 2009; BÉLO, 2014).

A segunda empreitada dos romanos à Britannia se deu em 43 d.C., ordenada pelo imperador Cláudio, com Aulo Plautio no comando, que iniciou os ataques contra a tribo bretã dos catuvellauni, que ocupava a região onde é hoje Hertfordshire. Essa tribo já tinha conquistado um grande território no sudeste da Inglaterra (SEALEY, 1997), contudo, a invasão não apresentou forte resistência e, assim, Cláudio conseguiu a submissão de onze tribos bretãs, fazendo delas tribos clientes, as quais poderiam ter suas próprias leis, tradições e moedas desde que pagassem tributos, ganhando assistência romana contra qualquer ataque externo, o que fez com que os bretões aceitassem a cortesia. Essas manobras renderam a Cláudio o título de Britannicus (DAVIES; ROBINSON, 2009; BÉLO, 2014).

A primeira revolta da tribo dos iceni, a tribo da rainha Boudica, contra os romanos ocorreu por volta de 47 d.C., quando Aulo Plautio foi substituído por Ostorio Scapula, que coordenou algumas ordens específicas, como destituir as tribos de suas armas de guerra, provocando uma ofensa aos iceni. Os romanos conseguiram driblar

Anos 90, Porto Alegre, v. 25, n. 47, p. 77-109, jul. 2018 
a revolta e Scapula recebeu o título de Corona Civica (DAVIES; ROBINSON, 2009; BÉLO, 2014).

Em 58 d.C., Suetônio Paulino tornou-se governador da Britannia e, logo em seguida, por volta de 60 d.C./61 d.C., após a morte de Prasutago, marido da rainha guerreira, ocorreu o cataclismo da revolta de Boudica.

\section{As rebeliões na Britannia}

Imagina-se que, com a chegada dos romanos à Britannia, houve uma variedade de reações em relação aos ideais sociais, assim como surgiu a possibilidade de qualquer pessoa rejeitar as normas dos invasores. Pode-se citar como exemplo as reações dos nativos, que deram origem a revoltas como a de Carataco e a de Boudica.

Carataco liderou uma rebelião contra o Império Romano anos antes de Boudica, rainha dos iceni (JOHNSON, 2012; BÉLO, 2014), mais especificamente em 51 d. C. (HINGLEY; UNWIN, 2005; BÉLO, 2014). Ele foi herdeiro da tribo dos catuvellaunios, junto com seu irmão, Togodumno, e teve rivalidade com os Atrebates, que se localizavam no sul da ilha. As moedas encontradas com a palavra CARA indicavam o seu domínio (ALDHOUSE-GREEN, 2006; BÉLO, 2014). Herdeiros de reis-clientes, Carataco e Togodumno se indispuseram com a política de Roma (PINTO, 2011; BÉLO, 2014). A resistência de Carataco na ilha demonstrava que seria difícil para os romanos controlar essa terra. Seu poder podia ser considerado alto em razão da quantidade de moedas encontradas pelos arqueólogos no sul da ilha (SALWAY, 1993; PINTO, 2011).

Para fugir dos romanos, Carataco foi se esconder nas terras dos silurios e, depois, nas terras dos ordovices, onde é hoje o País de Gales, local que os romanos pouco exploraram (ALDHOUSE-GREEN, 2006; BÉLO, 2014). Ele teve o apoio de inúmeras tribos bretãs e organizou resistência nessa localidade. Entretanto, o príncipe foi capturado em 51 d.C. em decorrência da traição da rainha dos brigantes, Cartimandua (TACITUS, 1952, livro 12, capítulo 36). Em vez de ser executado em Roma, Carataco foi poupado devido à 
demonstração de honra em prol de seu povo, em nome do qual foi aprisionado. Sentindo compaixão, Cláudio o perdoou e o deixou viver. No final, o príncipe demonstrou grande gratidão a Cláudio e a sua esposa, Agripina (TACITUS, 1952, livro 12, capítulo 36-37). Com isso, Carataco entrou para a história de Roma como herói de resistência ao invasor, pois era dotado de muitas virtudes, sobretudo pela renúncia da própria vida, ao mesmo tempo que conseguiu argumentar em defesa de sua pátria aos modos romanos. A diferença entre Boudica e Carataco, de acordo com os olhos de Roma, era que este último não demonstrava selvageria, confirmando atributos dignos de sua hombridade e de seu caráter masculino (PINTO, 2011; BELO, 2014).

Figura 1 - Vitral presente na prefeitura de Colchester com a figura de Carataco junto a outros heróis britânicos, assim como Eduardo, o Mais Velho

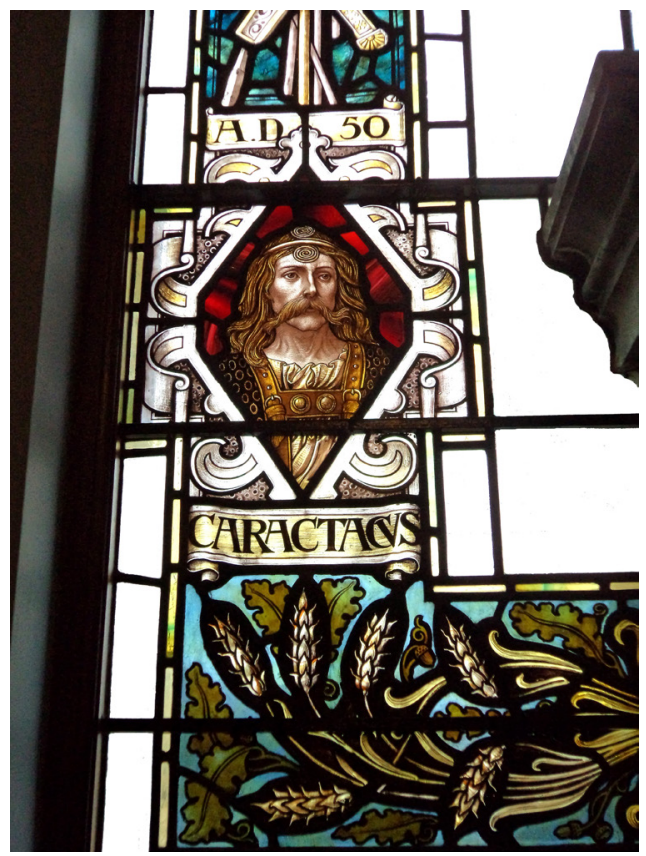

Fonte: BELO, 2012. 
Boudica, rainha bretã da tribo dos iceni e conhecida como a única mulher que enfrentou o Império Romano, juntou-se a nomes masculinos que provocaram reação semelhante em outras províncias romanas, tais como Viriato, na Ibéria, Vercingetorix, na Gália, Civilis e Armínio, na Germânia, e Carataco, na Britannia (BELO, 2014).

$\mathrm{Na}$ batalha, de acordo com Tácito, em $A$ Vida de Agrícola, a força dos bretões estava em sua infantaria, mas algumas tribos lutavam com carroças, como o fazia a própria Boudica. Seus comandantes sempre tinham um posto de honra e os combatentes eram meros retentores (TACITUS, 1914, capítulo 12). As carroças deixaram de ser usadas gradualmente pelos celtas da Gália, enquanto os bretões continuaram a utilizá-las, havendo nos escritos antigos informações de seu uso na Britannia. Diodoro e Tácito, por exemplo, demonstraram sua utilização desde a chegada de César à ilha, bem como na revolta de Boudica (FIELDS, 2011; BELO, 2014).

Tácito, ao descrever as batalhas contra os bretões, chama-os de covardes e destaca que eles somente lutavam por ganância e por rebeldia, enquanto os romanos lutavam por suas famílias (TACITUS, 1914, capítulo 15). Ao mencionar Boudica, salienta que ela persuadiu sua tribo a pegar em armas contra o inimigo. Tácito a apresenta como uma mulher de origem nobre e afirma que os bretões não reconheciam a distinção em relação ao sexo de seus governantes (TACITUS, 1914, capítulo 16). Além disso, explica que ela poderia até liderar os brigantes (não comenta sobre os iceni) para queimar a colônia e bramir em campo, porém, por ser mulher, nunca teria sucesso em batalha. No que diz respeito aos romanos, profere que lutavam como homens destemidos, homens que nunca falhariam em relação à liberdade e que nunca se tornariam penitentes (TACITUS, 1914, capítulo 31).

Tácito, em Anais, descreve o episódio do confronto do exército de Boudica contra o Império Romano no livro XIV, mas primeiramente menciona a investida romana à ilha de Mona, que fica a oeste do País de Gales e possui um legado que remonta à Idade da Pedra. Essa ilha era o coração do druidismo e, segundo Plínio, o Mais Velho, os druidas praticavam o culto à lua, que envolvia o brinde com chifres de animais, o uso de roupas brancas e também 
sacrifícios de animais. Provavelmente, Plínio viu o druidismo como um tipo de magia. Para César, os druidas eram um grupo de homens jovens que possuíam grande sabedoria e eram respeitados pelo resto da tribo; eram aqueles que discutiam todas as disputas, públicas e privadas (DAVIES; ROBINSON, 2009; BELO, 2014).

Tácito afirma que a ilha estava densamente povoada e acolhia muitos refugiados (TACITUS, 1952, livro 14, capítulo 29). Coincidentemente ou não, esse episódio ocorreu ao mesmo tempo em que Boudica e seus aliados começaram a destruir os assentamentos romanos. Entretanto, essa coincidência foi de especial significado para as primeiras vitórias dos bretões (BELO, 2014, p. 62).

$\mathrm{O}$ autor descreve as mulheres da ilha de Mona usando uma túnica negra, cabelos despenteados e com tochas nas mãos, o que dá a impressão de que eles foram pegos de surpresa durante a noite. Os druidas foram narrados com suas mãos levantadas para o céu, gritando terríveis maldições. O general romano diz aos soldados para não temerem um bando de mulheres fanáticas. É mencionado que os bosques onde os habitantes de Mona devotavam suas superstições, bem como seus altares e seus deuses, foram demolidos com a intenção de acabar com a religião dos nativos (TACITUS, 1952, livro 14 , capítulo 30 ).

Aldhouse-Green (2006) ressalta que, abolindo os valores básicos dos bretões, como a religião, seria mais fácil e consistente a introdução dos valores ligados ao "tornar-se romano". Essa questão estava também associada à liberdade que os druidas tinham em se locomover de uma tribo a outra, levando informações e, sobretudo, a imposição religiosa romana de ostentação de Cláudio, que foi proclamado um deus por Roma. Essa obrigação já era cobrada dos trinovantes, os quais viviam na área onde o templo de Cláudio foi construído, o que pode ter facilitado a junção de forças desses com os iceni para a revolta de Boudica. O principal propósito desse culto imperial era encorajar a lealdade e aproximar a aristocracia local aos romanos, para que dividissem as responsabilidades (ALDHOUSE-GREEN, 2006; BELO, 2014).

Tácito salienta que, durante a empreitada à ilha de Mona, Suetônio Paulino soube da rebelião na província causada pelas tribos dos iceni e trinovantes. $\mathrm{O}$ autor assinala que a rebelião se 
iniciou após a morte do rei Prasutago, marido de Boudica. Ele teria deixado o Império Romano como co-herdeiro de seus bens, junto a suas filhas, para evitar que seu reino sofresse ataques depois de sua morte. Todavia, após o seu óbito, os oficiais romanos quiseram tomar o reino dos iceni como um prêmio de guerra, açoitando sua viúva Boudica e violentando suas duas filhas, além de seus parentes e o resto da tribo terem sido tratados como escravos (TACITUS, 1952, livro 14, capítulo 31).

Os iceni foram degradados e reduzidos ao status de província, o que resultou em sua rebelião junto aos trinovantes e outros; o que emerge aqui é o tema da liberdade contra a escravidão, também enfatizado no diálogo de Boudica em Dião Cássio. Os iceni tiveram seu destino mudado, passando de prósperos, autônomos e dignos para um contexto de escravidão e humilhação (JOHNSON, 2012; BELO, 2014).

Prasutago fechou com os romanos um contrato antes de sua morte, o qual consistia em deixar-lhes parte de suas terras. $\mathrm{O}$ restante foi deixado para suas filhas e, de acordo com Tácito, Boudica não teve nenhuma relevância nesse contrato, o que leva a crer que os romanos teriam forçado Prasutago a concordar com esse documento ou que o marido a tenha deixado de lado por saber que ela era contra. $\mathrm{O}$ rei poderia estar interessado na abrangência de sua influência em relação a Roma, mesmo que sua posição estivesse longe de ser independente. A relação de governador da província com o cliente era pessoal e não dinástica, por isso, quando o primeiro morresse, os termos de aliança teriam que ser reconsiderados (ALDHOUSE-GREEN, 2006; BELO, 2014).

Pode-se frisar que foi a um só tempo ingênua e fatídica a aceitação do contrato por Prasutago, pois os termos devem ter sido revistos posteriormente e os romanos podem não ter reivindicado metade do território, e sim sua totalidade. Essa é uma questão que não está explanada com detalhes nos documentos históricos, portanto, não é possível saber a verdadeira razão do acontecimento entre os iceni e os romanos (BELO, 2014, p. 63). 


\section{A violência contra Boudica e suas filhas}

Deciano Cato, um oficial de finanças, procurator Britanniae, responsável por todo e qualquer trabalho ligado a dinheiro e rendimento, em particular por taxação, era encarregado de fazer com que a Britannia pagasse o que devia e, se possível, esgotar suas riquezas e mandá-las para a bolsa central de Roma. Ele cobrava o pagamento dos homens do exército, as taxas de terra e outros tributos, com o intuito de arrecadar cada vez mais, visto que isso lhe traria sucesso na província, além de promoção, em geral, para fora da ilha, porventura um lugar melhor e menos nebuloso (ALDHOUSE-GREEN, 2006; BELO, 2014).

Em trabalho na Anglia do Leste, Cato viu a morte de Prasutago como um modo de ganhar dinheiro e, talvez, adquirir glória, adicionando o território dos iceni à província na ausência do governador e do poder de guerra romano, os quais estavam na ilha de Mona. O resultado foi a recusa, por parte de Boudica, da entrega das terras, ocasionando o seu açoitamento e a violação de suas filhas. Esse episódio deu início à formação do exército liderado por ela e, consequentemente, à destruição de três assentamentos romanos (ALDHOUSE-GREEN, 2006; BELO, 2014).

O evento ocorrido com Boudica e suas filhas é considerado, por estudiosas da Antiguidade, tais como Aldhouse-Green (2006) e Johnson (2012), o pior tipo de humilhação, não apenas pelo testemunho da ferocidade imperial, mas também pela resposta dramática e expositiva a uma mulher reconhecida por desprezar os romanos (JOHNSON, 2012). Até mesmo para os padrões de Roma, o estupro era considerado um crime bruto de guerra, enquanto o açoitamento era uma punição executada em decorrência de uma ofensa hedionda, assim como o assassinato. $\mathrm{Na}$ lei do Império Romano, o espancamento até a morte era um método de punição para quem havia cometido o parricídio, que consiste em crime contra os pais (ALDHOUSE-GREEN, 2006). Dessa forma, pensa-se que os centuriões que executaram o ato contra Boudica e suas filhas, com a disciplina draconiana que tinham, somente poderiam tê-lo feito sob uma repressão muito densa de quem os comandava, ou cegamente cumpriam as ordens de alguém que ocupava uma 
posição mais elevada, uma vez que não era de interesse romano ter soldados que questionassem ou pensassem a fundo sobre ordens dadas (BELO, 2014, p. 64-65).

Ainda que seja um crime lamentável, o estupro é comum em contextos de hostilidade, estando menos associado com o sexo em si e mais com violência, abuso, insulto, desonra, controle e criação de vítimas. $\mathrm{O}$ consequente risco de gravidez faz com que esteja também associado a violação e potente interrupção de uma linhagem (ALDHOUSE-GREEN, 2006). Sendo assim, os oficiais valeram-se de um poder que, segundo Johnson (2012), contaminaria as garotas com um descendente bastardo e romano. Mesmo que esse crime seja visto como horrendo, embora um crime de guerra comum, Tácito e Dião Cássio o expuseram abertamente em seus escritos, o que nos faz questionar por qual razão, já que esse tipo de abuso físico também reduz o caráter humano dos romanos. Talvez seu objetivo tenha sido mostrar que a conquista era o fator romano primordial e que ela aconteceria de qualquer maneira, ainda que para isso fosse necessário ultrapassar os limites da ética e da moral (BELO, 2014, p. 65).

De acordo com Adhouse-Green (2006), o estupro foi especialmente significativo, chocante e degradante para as adolescentes, a mãe, a casa real de Prasutago (DAVIES; ROBINSON, 2009) e toda a tribo, não apenas porque eram mulheres, mas também porque eram crianças, provavelmente virgens na puberdade. Elas representariam a futura geração da tribo dos iceni, futuras esposas e mães, e, por esse motivo, os romanos quiseram comprometê-las e contaminá-las com seus genes, fazendo com que carregassem a lembrança da agressão pelo resto de suas vidas (BELO, 2014, p. 65).

No discurso feminista, o estupro é a maior expressão da ordem patriarcal, visto como um crime que reduz a mulher a um estado degradante. $\mathrm{O}$ movimento vê o estupro como o crime mais extremo direcionado a uma mulher, ou seja, um ato de violência e repugnância, sendo um dos problemas mais difíceis encarados pelo grupo. A celebração do estupro na história, na música e na ciência, de acordo com Adrea Dworkin (1989), constitui-se como um paradigma de articulação do poder sexual masculino, como um absolutismo cultural. Robin Morgan (1977) descreve o estupro 
como a última metáfora para dominação, violência, subjugação e possessão (CAHILL, 2001; BELO, 2014).

Segundo Fields (2011), a natureza da visão do mundo romano não era de este ser passivo, mas de exercer poder para conquistar e dominar. As invasões romanas significavam força e imposição e não a manutenção da paz e da ordem em Roma. O mundo não era tentado à paz como o era à agressividade e à submissão. Por essa razão, os romanos sentiam que podiam ameaçar os reinos dos clientes como bem desejassem. O que neles consideramos beligerante, bruto e sanguinário era fundamental para sua cultura e sistema social. Os romanos eram muito habilidosos na arte da guerra, a qual dava poder ao Estado, e esse poder não era exercido se ela não pudesse ser usada, já que a agressão era fundamental para a base lógica da política estrangeira romana. Além disso, a guerra era a oportunidade de colocar em prática o que aprendiam desde a infância, isto é, liderar e mandar. Esse comportamento também os fizera pedantes, patriarcalistas, brutais e, ocasionalmente, psicopatas (FIELDS, 2011; BELO, 2014).

\section{A rebelião de Boudica}

A guerra começou após o episódio de agressão contra Boudica e suas filhas, fazendo com que a rainha dos iceni rapidamente levantasse seu povo e se unisse aos seus vizinhos trinovantes. Ao descrever a passagem da rebelião na Britannia, Dião Cássio inicia afirmando que um grande desastre estava acontecendo na ilha, já que duas cidades romanas tinham sido saqueadas, oito mil romanos e seus aliados haviam sido derrotados e a ilha, perdida. Todavia, o mais vergonhoso, cita Cássio, era o fato de todo esse desastre ter sido tramado por uma mulher (CASSIUS DIO, 1914-1927, livro 62, capítulo 21).

Segundo o autor, uma das causas da guerra foi o confisco de uma soma de dinheiro dada por Cláudio aos bretões, a qual deveria ter sido paga. A pessoa que chefiaria os nativos, persuadindo-os a lutar e os conduzindo para a guerra, era Boudica, uma bretã de família real, de grande inteligência em comparação a outras mulheres (CASSIUS DIO, 1914-1927, livro 62, capítulo 22). 
Tácito menciona que a rebelião se iniciou em Camulodunum, que abrigava ex-oficiais romanos, os quais tratavam os trinovantes como escravos. Além disso, essa instalação resguardava o templo de Cláudio, símbolo de lei romana e de opressão aos autóctones, que também significava a vitória e o triunfo dos romanos sobre os nativos. Todavia, a rebelião de Boudica representou um cataclismo na administração da província. Camulodunum foi destruída no primeiro impacto, de modo que o odiado assentamento foi arrasado e queimado até o chão, sendo a população, sem distinção de sexo ou idade, dizimada de formas variadas, como crucificação, enforcamento, ateamento de fogo e esfaqueamento (FIELDS, 2011; BELO, 2014).

Tácito dá a desculpa de que era muito simples invadir esse assentamento, pois ele não era cercado por muros (TACITUS, 1952, livro 14, capítulo 31). Para adicionar, o autor narra a invasão dos nativos como algo hediondo, descrevendo o sofrimento de mulheres e crianças, além de ilustrar a vermelhidão em que o mar ficou e como a maré levou os corpos mortos (TACITUS, 1952, livro 14, capítulo 32).

Pelas palavras de Cássio, a ação mais bestial dos bretões foi pegar as mulheres mais nobres, despi-las, pendurá-las, decepar seus peitos e colocá-los em suas bocas como se os estivessem comendo. Logo, empalaram-nas em lanças afiadas, atravessando seus corpos. Tudo o que faziam era acompanhado de sacrifícios, banquetes e comportamentos arbitrários, não apenas em seus lugares sagrados, mas particularmente no arvoredo de Andraste, que era para eles a deusa da Vitória, a qual resguardavam com excepcional reverência (CASSIUS DIO, 1914-1927, livro 62, capítulo 27).

De acordo com Aldhouse-Green (2006), a mutilação dos seios das mulheres romanas e o seu empalamento parecem representar um estupro simbólico em vingança ao que foi feito com as filhas de Boudica (ADHOUSE-GREEN, 2006; DAVIES; ROBINSON, 2009). Nesse sentido, ao narrar esse episódio, Cássio quis mostrar o quanto os bretões eram "bárbaros", ao cortarem os seios e colocá-los na boca, como se fosse um ritual canibalista, já que esse estereótipo não fazia parte do que era conhecido como humanidade (ALDHOUSE-GREEN, 2006). 
Sabendo da rebelião, Paulino não quis guerrear contra os bretões de imediato em razão da falta de homens e de comida para a batalha, tendo assim mais tempo para pensar em uma estratégia mais eficiente. Sua dificuldade estava ligada à II Legião, de Poeno Postumo, que não queria juntar suas forças. Outro ponto refere-se à IX Legião, sob o comando de Petillio Cereales, que tinha acabado de ser atacada pelos iceni e estava imobilizada no leste das Midlands. O exército de Suetônio consistia na XIV Legião e seus auxiliares (SEALEY, 1997), que poderiam ser convocados a qualquer momento (BELO, 2014, p. 72).

Como Suetônio estava longe do palco de guerra, ele mandou um exército com poucas guarnições, comandado por Cato Deciano, o mesmo que deu origem à revolta, porém, seu ímpeto contra os bretões falhou e a impopularidade adquirida fez com que ele voltasse para a Gália. Logo, o outro alvo dos bretões era Londinium, que não era caracterizada como um assentamento romano, embora fosse um centro importante de homens de negócios e mercadorias. Tácito, entretanto, salienta que Suetônio preferiu sacrificar Londinium para salvar, mais tarde, toda a província, pois estava com um exército muito pequeno. Os homens de Londinium acompanharam Suetônio, já as mulheres e as crianças que ficaram foram massacradas pelo exército de Boudica, segundo essa fonte. Contudo, Verulamium teve o mesmo destino (TACITUS, 1952, livro 14, capítulo 33).

É muito interessante a maneira como Tácito descreve os nativos, salientando que eles adoravam a pilhagem e nada mais. Eles ignoravam fortes e guarnições, sendo a pilhagem a garantia de riqueza para os bretões, mas a proteção deles era fraca. Outra característica, segundo o autor, é que eles não tinham o costume de vender prisioneiros ou de praticar outro tipo de troca relacionada a bens de guerra. Nas palavras do escritor, eles pareciam ansiosos pelo momento de cortar gargantas, enforcar, queimar e crucificar (TACITUS, 1952, livro 14, capítulo 33).

Tácito menciona ainda que a empreitada dos romanos contra os nativos foi estrategicamente planejada. Suetônio Paulino recrutou todas as brigadas disponíveis e pediu ajuda para as tropas auxiliares que estivessem mais próximas. Além disso, escolheu de forma perspicaz o campo de batalha, que, ao fundo, era tomado 
por uma floresta densa, impedindo a presença do inimigo, a não ser na parte da frente do exército. $\mathrm{O}$ autor cita que o número de nativos era impressionante e que estes trouxeram as mulheres para assistir à sua vitória (TACITUS, 1952, livro 14, capítulo 34).

No que se refere a Boudica, Tácito afirma que ela andava de um lado para o outro numa carroça, com suas filhas à frente, entre as tribos, citando que entre os bretões era comum uma mulher no comando de guerra e que ela era descendente de homens poderosos, alegando, ademais, que ela assegurava não lutar pelo seu reino, mas por uma prosperidade. Destacou também que ela lutava como uma pessoa comum pela perda de sua liberdade, pelo seu corpo ferido e pelas filhas ultrajadas, acrescentando que, naquele momento, pessoas idosas estavam sendo mortas, virgens violentadas e, apesar disso, ela tinha a garantia de que os deuses iriam conceder a vingança que eles mereciam. Segundo as expressões do autor, Boudica continuou questionando quantas pessoas estavam lutando e por quê. Logo, ela supunha que os nativos iriam vencer a batalha ou perecer, de modo que lutar era o que ela, uma mulher, planejava fazer, se acontecesse o contrário deixaria os homens viverem na escravidão, mas duvidava de que eles iriam conseguir (TACITUS, 1952, livro 14, capítulo 35).

É interessante também citar as palavras de Suetônio Paulino, ao mencionar que na linha de soldados dos bretões havia mais mulheres para lutar do que homens (TACITUS, 1952, livro 14, capítulo 36), como se essa característica fosse uma fragilidade do oponente. $\mathrm{O}$ autor deixa claro que os romanos não pouparam as mulheres e que a vitória foi gloriosa comparada aos embates passados. Além disso, Tácito menciona que Boudica se envenenou e proclamou o triunfo romano (TACITUS, 1952, livro 14, capítulo 37).

Não se tem resquícios de onde foi travada essa batalha, mas provavelmente ocorreu em algum trecho da estrada romana, denominada Watling Street ou Wrcelinga Stræt, em inglês arcaico. Conhecida atualmente por A2 e A5, a estrada principal se estende de Dover-Portus Dubris a Wroxeter-Viriconium, via Tâmisa e ponte de Westminster, que no passado unia Londinium às Midlands, a qual também passava por Verulamium (SEALEY, 1997; FIELDS, 2011) e era uma das mais importantes estradas romanas, ligando Londinium 
ao noroeste, junto a outra que ligava esse centro comercial ao nordeste, a caminho de Camulodunum (FIELDS, 2011; BELO, 2014).

\section{Figura 2 - Indicação da Watling Street em St. Albans, Inglaterra}

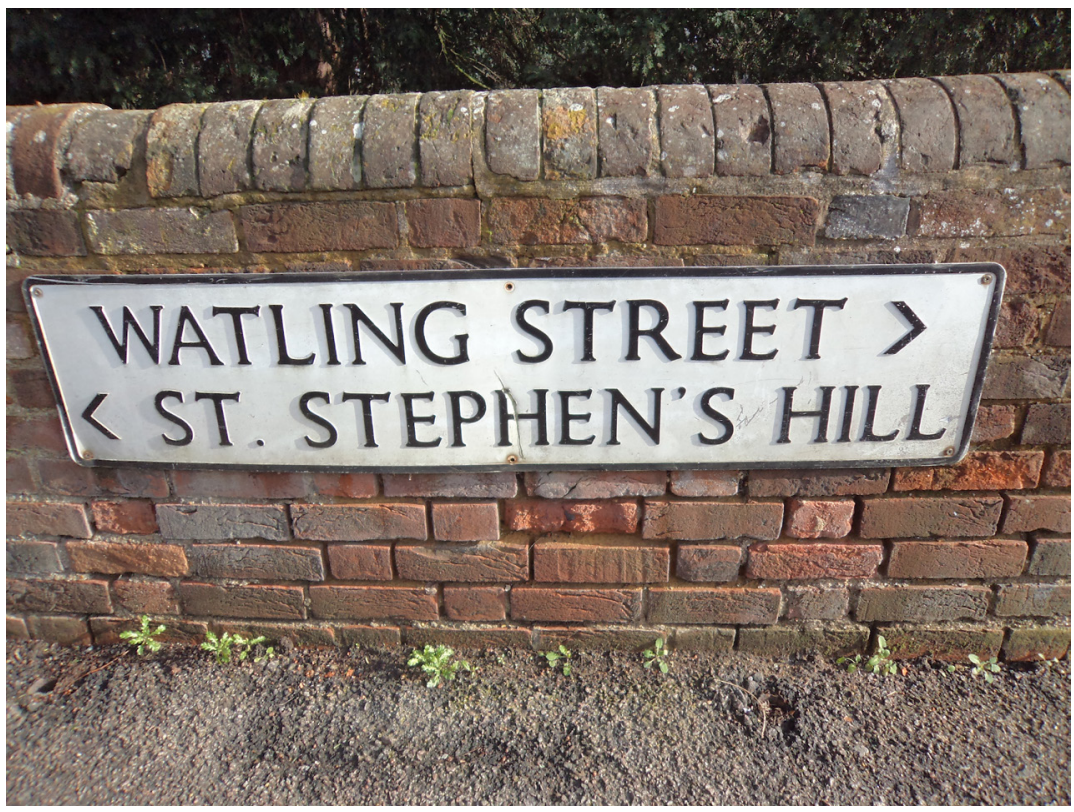

Fonte: BELO, 2015.

Para os iceni, essa batalha foi um desastre inqualificado, visto que eles não semearam a colheita daquele ano (SEALEY, 1997; DAVIES; ROBINSON, 2009) e, portanto, sua derrota foi seguida por fome. É provável que séculos tenham decorrido até que a população conseguisse se recompor completamente (SEALEY, 1997). Contudo, questiona-se se esse foi um bom plano para os bretões, tendo em vista que uma política pacífica poderia ter infligido uma agonia duradoura, o que também não os faria vencer a guerra (FIELDS, 2011; BELO, 2014).

O território da tribo dos iceni foi dividido em grandes áreas de terras definidas por grades retangulares, atitude tomada pela 
administração romana para facilitar o restabelecimento depois da guerra. Entretanto, o que os restos arqueológicos indicam é que o projeto não foi completado. Ao que parece, a construção foi parada durante o governo de Agrícola, entre o período aproximado de 77 d.C a 83-84 d.C. O mais interessante é que se sugere que a última guarnição romana foi afastada da região, pois foi encontrado em Camelon, Escócia, um forte construído durante esse período, com cerâmicas dos iceni, as quais não chegaram à região por meios comerciais, mas, sim, carregadas pelas tropas que deveriam ter servido ali (SEALEY, 1997; BELO, 2014).

Os achados arqueológicos do final do primeiro século, na capital dos iceni, chamada Venta Icenorum, em Caistor St. Edmund, mostram trabalhos em metal e moedas que caracterizam o local como um grande centro da Idade do Ferro, precedido por um grande forte romano construído no final da revolta de Boudica. Antes do término do primeiro século, o povoado teve um fórum, uma basílica e uma muralha com 14 hectares, uma das menores muralhas da província. Seu pequeno tamanho mostra o impacto da revolta na população dos iceni na economia e na moral da aristocracia. Contudo, ela se regenerou completamente entre os séculos II e V, passando a ser o local mais notável para trabalhos em joias de ouro e prata, os quais foram achados em sepultamentos de Snettisham, Mildenhall e Hoxne (SEALEY, 1997; BELO, 2014).

Pelas perspectivas dos autores sobre a rebelião de Boudica, parece que as de Tácito são mais palpáveis, apesar de que foi a descrição de Cássio sobre a guerreira e suas atrocidades que perdurou posteriormente (BELO, 2014, p. 74).

As perspectivas de comum dominação masculina da sociedade em que Tácito e Dião Cássio viviam fizeram com que, em suas narrativas, reproduzissem a visão patriarcal romana sobre o papel da mulher no mundo mediterrânico da época, além de serem influenciados por discursos expansionistas (PINTO, 2011). Sendo assim, descreveram Boudica como uma figura "bárbara" e incomum no que tange à liderança de um exército, e, assim, autores posteriores, seguindo os mesmos pensamentos, quase sempre a apresentaram como algo diferente, uma anomalia, pois ela ultrapassou os limites do papel feminino da sociedade onde esses escritores 
viviam. Segundo Pinto (2011), a descrição desses autores parecia seguir modelos greco-latinos de rebeliões nas províncias romanas (BELO, 2014, p. 75).

Entretanto, mesmo sendo muitas vezes descrita de forma pejorativa, Boudica foi constantemente relembrada, da Antiguidade até os dias de hoje, em razão do seu gênero e pelos seus atos, ou seja, pelo fato de ela ter sido uma mulher que levou seu povo à batalha. Em relação aos escritores romanos, pode-se dizer que a preocupação de Cássio era com a retórica e com o exagero, porém, Tácito tinha conhecimento das táticas de guerra e de comando de Suetônio Paulino (JOHNSON, 2012; BELO, 2014).

Tácito salienta que Boudica cometeu suicídio envenenando-se depois da última batalha (TACITUS, 1952, livro 14, capítulo 37), já que essa poderia ser uma das maneiras de não ser pega pelos romanos e levada para Roma. Dião Cássio menciona que ela morrera posteriormente, sem especificar a causa de sua morte (CASSIUS DIO, 1914-1927, livro 62, capítulo 12). O passado esvai-se e o que nos resta são os fatos, os quais devem ter uma força retroativa que inspira o estudo e a manutenção do que se foi (BELO, 2014, p. 75).

\section{O contato e seus vestígios}

A hostilidade e a represália poderiam assumir uma pacificação com a definitiva instalação e administração da província por Roma. Entretanto, a violência poderia ter assumido uma outra cena, ou um caráter diferente daquele com armas e confrontos corporais, pois na Britannia, antes da chegada dos romanos, habitavam tribos independentes, com atividades, religiões, costumes e tradições distintos daqueles dos invasores, atividades as quais tendiam a ser continuadas durante o cotidiano dessas tribos. O choque cultural assume, dessa forma, também uma violência quando um dos grupos admite que a ordem e as leis devam ser seguidas à sua maneira.

Pode-se imaginar a dificuldade da convivência de grupos totalmente distintos em um mesmo território. $\mathrm{O}$ embate acontece porque cada pessoa é formada dentro de um contexto sociopolítico específico, o qual influencia no modo de como se considerar 
apropriada certa norma de comportamento. A ideia de normalizar o discurso de identidade pode ser, num primeiro momento, a entrega de um poder sem garantias, que carrega a impressão de estereótipos sociais, contudo, isso é amenizado com a ideia de agência, ou seja, quando cada pessoa tem a habilidade de fazer a diferença em sua situação através de certos recursos (literal e metaforicamente), adequando-se a eles dentro das estruturas sociais (JOHNSON, 1989; DOBRES; ROBB, 2000; REVELL, 2016).

Todavia, a identidade é dinâmica, e a posição dos indivíduos dentro da comunidade pode depender de vários aspectos, tais como gênero, idade, ocupação, status, sexualidade e etnicidade (REVELL, 2016, p. 16). O impacto dos diferentes modos de vida, no que tange à cultura do "outro", pode ser visto em Tácito, que, ao descrever os germanos, por exemplo, salientou que eles não viviam em cidades, mas em assentamentos desorganizados, e que inexperientemente construíam suas casas (TACITUS, 1877, capítulo 16), classificando-os como não civilizados. Outro exemplo foi dado por García (1997), em relação ao grego Estrabão, que, ao abordar os cantabrianos da Península Ibérica, mencionou que aqueles que não tivessem cidade não eram considerados "civilizados", pois viviam como animais (GARCÍA, 1997, p. 162). ${ }^{1}$

A ideia de identidade está a cargo do discurso e de um grupo de ideias que envolvem ações e comportamentos trabalhados para usar certo tipo de cultura material (REVELL, 2016, p. 42). Todavia, Hingley (1997) ressalta que a existência da continuação das construções de casas redondas, típicas dos nativos, por exemplo, demonstrou a possibilidade da não resistência, ou mesmo da não imposição de uma cultura sobre a outra (HINGLEY, 1997; REVELL, 2016). Esse fato pode ser evidenciado pela cultura material de Vindolanda, em que os romanos começaram a incorporar esse tipo de edifício redondo nas suas próprias construções. Revell (2016) conclui que pode ter havido um processo de integração dos grupos, o que também pode ter levado a significativas transformações (REVELL, 2016, p. 55)2. 
Figura 3 - Sítio Vindolanda, norte da Inglaterra

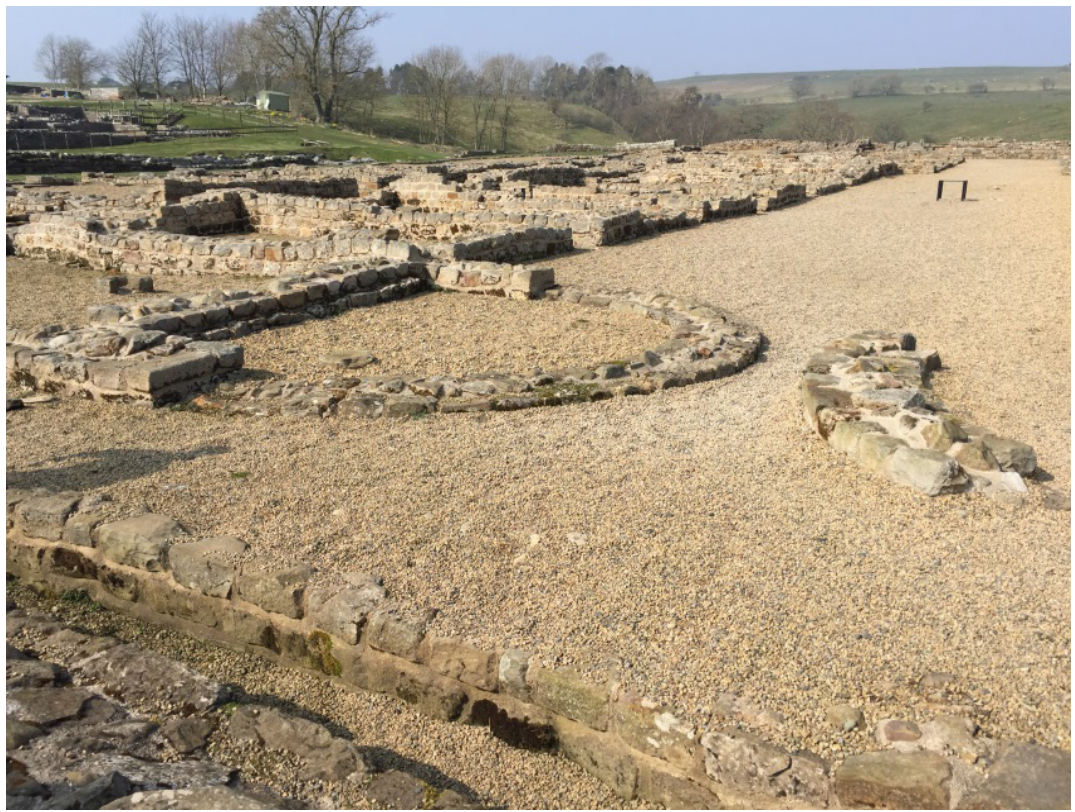

Fonte: BELO, 2017.

Em relação aos bretões, os seus modos foram mencionados por Allason-Jones (2012), que, citando Júlio César, transcreve que "grupos de dez ou vinte homens tinham grupos de mulheres em comum, e particularmente, irmãos juntamente com irmãos e pais com filhos, mas a criança nascida pertencia a casa da mulher, a qual ela foi primeiramente conduzida" (CAESAR, 1988, livro 5, capítulo 14; ALLASON-JONES, 2012, p. 467). Essa atividade de sexo livre também foi questionada por Julia Domna a uma esposa de chefe nativo da Caledônia, Argentocoxus, em Dião Cássio (CASSIUS DIO, 1914-1927, livro 77, capítulo 16.5), o que levou Allason-Jones (2012) a interpretar esses eventos com a hipótese da possibilidade de que as famílias bretãs poderiam ser matriarcais (ALLASON-JONES, 2012, p. 467). 
Outro exemplo desse fato está elucidado em "A vida de Agrícola", em que Tácito menciona que "os bretões não fazem distinção do sexo de seus líderes” (TACITUS, 1914, capítulo 16), como também em Anais, quando o autor relata que tanto Boudica quanto Cartimandua eram líderes de tribos bretãs, o que traz uma concepção contrária às mulheres romanas, que possuíam certos limites para a atuação política.

Quando diferentes grupos se juntam, podem surgir situações em que os limites dos pertences e exclusão devam ser articulados e controlados, ou seja, quando eles entram em contato uns com os outros, suas fronteiras são elaboradas através de ações e demonstradas mediante a cultura material (REVELL, 2016, p. 11).

Esse processo pode acontecer imediatamente, envolvendo encontros cara a cara entre tais grupos, mas o mais significante é a formação de fronteiras metafóricas. A criação do "outro" pode girar em torno da ideia das antíteses estereotipadas em relação às expectativas do grupo. As rotinas do dia a dia se tornam significativas quando o conhecimento do comportamento esperado é aprendido e reafirmado. $\mathrm{O}$ indivíduo aprende os ideais e as expectativas e os adota se ele passar a se identificar. Por outro lado, se mantém a distância do grupo, ele terá diferentes rotinas como afirmação, a qual somente pode ser entendida através de comportamentos normativos. Isso parece apresentar a identidade como uma expressão consciente, ou que um indivíduo é livre para escolher com qual grupo se identifica. Entretanto, muito dessa escolha pode ser inconsciente e se tornar significativo em momentos em que o indivíduo se confronta com uma situação na qual sua identidade é contestada (REVELL, 2016, p. 11).

Nessa perspectiva, dois exemplos de mulheres nativas que se juntaram, ou mesmo casaram-se com indivíduos de outras partes do mundo, os quais já estavam internalizados como cidadãos romanos, serão aqui notificados, evidenciando o pensamento de outros estudiosos sobre esse tema. Sendo assim, a primeira amostra da heterogeneidade cultural dessa província está no jazigo, feito em pedra, de Julia Velva (RIB ${ }^{3}$ 688) e família, que foi encontrado em 1922, ao fazerem uma nova estrada a sudeste de Mount, em direção a South Bank, York, e que atualmente se encontra exposto 
no museu de Yorkshire ${ }^{4}$, demonstrando que Aurelio Mercuriale, que parece ser um nome romano, refere-se a si mesmo no epitáfio como herdeiro de Julia Velva e que ele construiu esse túmulo para ele e sua família. A falta de um nome em comum entre ela e seu herdeiro denota que ela não era nem sua filha nem sua irmã, mas parte da família. Ela poderia ser sua sogra, mas a expressão "viveu como a mais obediente" era mais comumente utilizada para esposas ou amantes livres. Algumas evidências epigráficas de Roma apontam que mulheres livres poderiam fazer parte da família e ser enterradas juntas (ALLASON-JONES, 2005, p. 12-13). Adicionando-se o fato de que dificilmente seria uma mulher que deixaria uma herança para um homem, e sobrepondo o comentário feito no site Roman Inscription of Britain, que salienta que Velva não era um nome latim, e, sim, celta, sugere-se que Julia Velva se tratava de uma mulher livre e que não seguia as leis de Roma de forma rigorosa ${ }^{5}$. 
Britannia: violência, poder e contato

Figura 4 - Jazigo familiar de Aurelio Mercuriale com Julia Velva

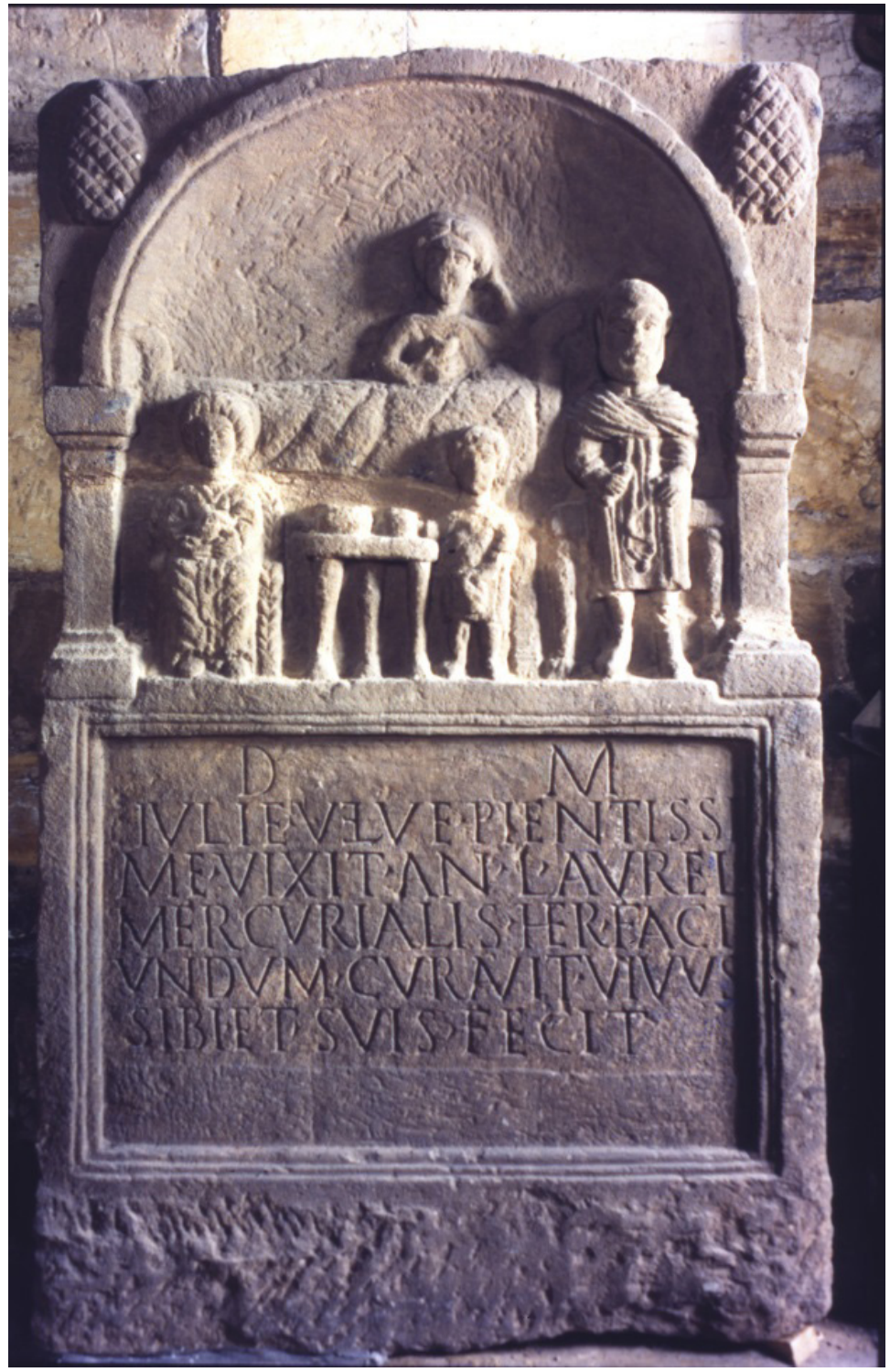

Fonte: York Museums Trust ${ }^{6}$

Anos 90, Porto Alegre, v. 25, n. 47, p. 77-109, jul. 2018 


\section{Epitáfio}

$\mathrm{D}$ (is) $\mathrm{M}$ (anibus)

Iulie Velve pientissi-

me vixit an(nos) L Aurel(ius)

Mercurialis he(es) faci-

undum curavit vivus

sibi et suis fecit ${ }^{7}$

\section{Tradução}

Aos deuses Manes e a Julia Velva: ela viveu como a mais obediente durante 50 anos. Aurelio Mercuriale, seu herdeiro, construiu esse monumento, e durante sua vida fez isso para si e para sua família. ${ }^{8}$

Julia Velva mostra-se no relevo, descrito em Eboracum como um jazigo em arenito, exposta em um sofá com uma jovem garota, um servo e Aurelio Mercuriale. Ela está com os cabelos separados ao meio e com o torso visível ao sol, reclinado em um sofá, apoiando a cabeça no braço esquerdo e segurando um frasco de vinho na mão direita. O sofá parece ser muito espesso, com lados altos e pernas nobres. $\mathrm{Na}$ frente do sofá, da esquerda para a direita, está uma jovem sentada em uma cadeira de cesta e apertando uma ave de estimação, em uma mesa de três pés. Os pratos encontram-se na mesa e um menino está de pé com a mão direita sobre a mesa e segurando uma jarra na sua mão esquerda, enquanto Aurelio Mercuriale está na frente de uma mesa maior com pés de garra, segurando um pergaminho na mão direita ${ }^{9}$. Nos relevos romano-britânicos, tanto o homem quanto a mulher podem aparecer deitados em sofá, mas é raro um homem surgir sentado em uma cadeira, posto que algumas cadeiras eram feitas apenas para mulheres (ALLASON-JONES, 2005, p. 86).

Em relação aos casamentos entre romanos e nativas, o maior exemplo pode ser evidenciado pelo sepultamento de Regina, encontrado em South Shields, datado de II d.C., que, além das inscrições, apresenta sua imagem com roupas, joias e mobília, caracterizando 
um verdadeiro altar. A inscrição cita que ela era uma nativa da tribo dos catuvellauni que morreu aos trinta anos (RIB 1065) e era uma mulher livre, esposa de Barates, de Palmira (ALLASON-JONES, 2012, p. 470).

Figura 5 - Altar de Regina, encontrado em South Shields, datado do século II d.C

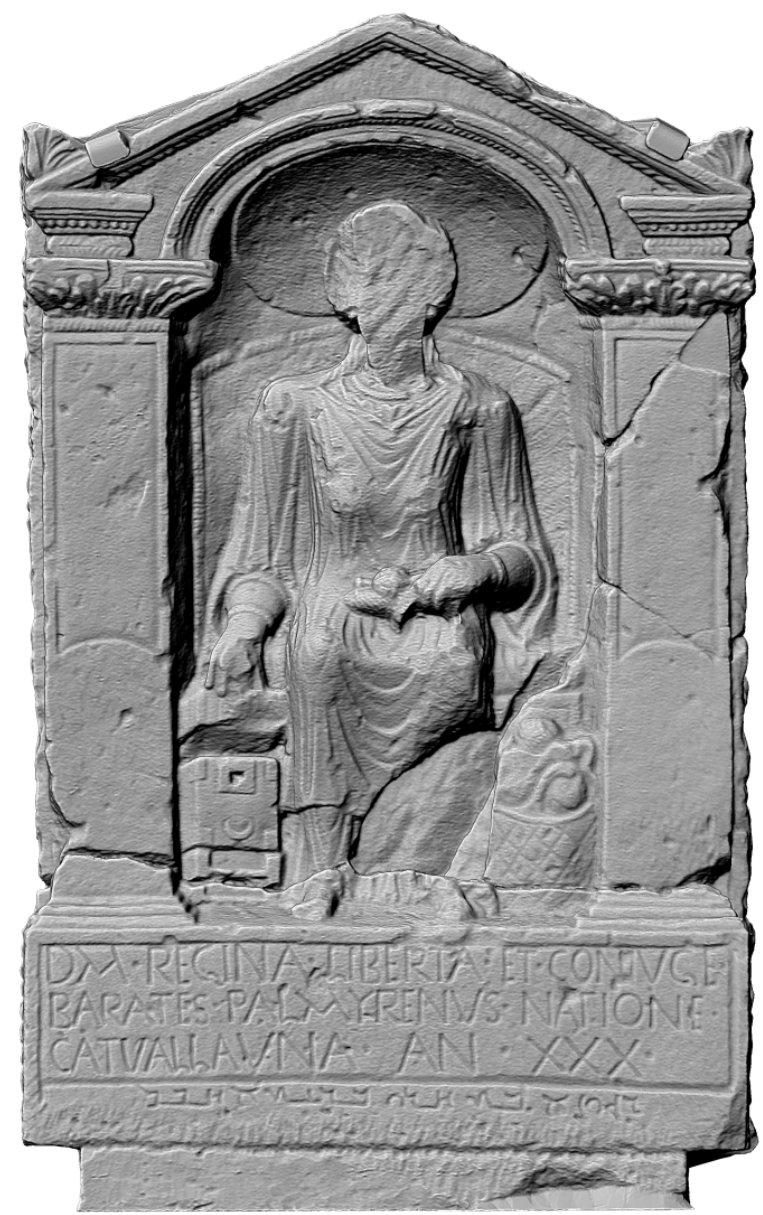

Fonte: Newcastle University ${ }^{10}$ 
O altar de Regina está dividido em quatro fragmentos e emoldurado em duas pilastras, nas quais a falecida fica sentada em uma cadeira de vime voltada para frente. Ela veste um manto com mangas longas sobre uma túnica, o qual chega até os pés. Em volta de seu pescoço, há um colar e pulseiras em seus punhos. Em seu colo, estão uma roca e um fuso. Além disso, enquanto do seu lado esquerdo encontra-se um cesto de trabalho, com novelos de lã, com sua mão direita, ela segura um porta-joias aberto. Ela possui uma grande auréola em volta de sua cabeça, mas seu rosto está cortado ${ }^{11}$.

\section{Epitáfio}

$\mathrm{D}$ (is) $\mathrm{M}$ (anibus) Regina liberta et coniuge

Barates Palmyrenus natione

Catvallauna an(norum) $\mathrm{XXX}^{12}$

\section{Tradução}

Barates de Palmira (construiu este monumento), em dedicação aos deuses Manes, para a liberta Regina, sua esposa, da nação catuvelauna, com trinta anos de idade ${ }^{13}$.

De acordo com Allason-Jones (2005), Regina poderia ter sido, primeiramente, por um determinado tempo, uma escrava, com um aparente comércio doméstico em atividade, já que as inscrições demonstram que ela era uma mulher livre. No final do século II d.C., era difícil compreender como um membro de uma tribo bretã, nascida livre, poderia ter se tornado uma escrava. Allason-Jones (2005) sugere que o único modo de isso ter acontecido seria a venda dela pelos pais. Acrescenta que essa prática foi banida por Roma até 313 d.C., mas, por evidências em Noricum e em outras partes do Império, parece que essa atividade ocorria em todas as regiões entre os séculos II e III d.C. (ALLASON-JONES, 2005, p. 14). Essa hipótese sobre Regina também pode ser empregada no caso de Julia Velva.

As duas nativas, tanto Regina quanto Julia Velva, parecem ter vivido uma experiência discrepante, que foi expandida por 
causa de uma identidade oposta. Deve-se ter em mente que múltiplos fatores podem ser reconhecidos como aqueles que formam as experiências de vida de uma pessoa, dentre os quais alguns podem ter sido impactantes para a identidade delas, como, por exemplo, a disparidade em relação a status, localização, religião, origem, língua, gênero, idade, entre outros (MATTINGLY, 2004; REVELL, 2016). Outra explicação diz respeito ao fato de que Regina pode ter sido uma vítima do impacto do imperialismo romano e das relações de poder, que podem ser caracterizados como uma transformação que não foi neutra, mas que serviu como uma estratégia de controle pelas autoridades imperiais (REVELL, 2016, p. 56). O casamento entre romanos e nativas poderia ser potencialmente um processo de remoção da identidade nativa. Embora o grupo tenha permanecido, as relações dentro dele e, potencialmente, entre os grupos podem ter sido refeitas em uma ideologia romana, cuja assimilação, passível de ser variável, pode ter sido incentivada pelo mecanismo do esquecimento.

$\mathrm{Na}$ lápide, ela está vestida como uma típica matrona romana, embora use um torc em volta do pescoço. A vestimenta está associada aos símbolos tradicionais das matronas romanas, assim como a cesta de lã, a roca e o fuso, que também estão ligados ao contexto funerário de Palmira, de onde seu marido era ${ }^{14}$. Regina possui um traje longo, invisível pelo pescoço, com a exceção de quando se vê o broche de fixação, e as mangas ajustadas que terminam antes dos braceletes. Esse traje interno é suportado pela bainha do vestuário externo (ALLASON-JONES, 2005, p. 107).

Achados em sepulcros sugerem que muitos braceletes eram utilizados ao mesmo tempo, mas as esculturas mostram que um bracelete em cada antebraço era o modo preferido de se usar, assim como os de Regina, pois ele poderia ser muito caro, bem elaborado e com motivos e decorações diversos (ALLASON-JONES, 2005, p. 118). Os broches não parecem ter sido usados como enfeites, mas como algo utilitário para juntar as peças de roupas, sendo geralmente feitos de cobre, fusão de metais, latão, bronze e com acabamento de prata. É provável que os broches tenham se tornado menos populares entre as mulheres no final do século II d.C., exceto os 
broches em forma de arco, que foram encontrados massivamente em sepultamentos masculinos (ALLASON-JONES, 2005, p. 121).

A roupa, os adornos e mesmo a atividade ali representada, encontrados nesses tipos de cultura material, como o altar de Regina, podem indicar uma abstração de identidade que pode ser aprendida e internalizada, pois o modo de se vestir é parte do processo de socialização, isto é, a adoção de diferentes modos de vestimenta pode evidenciar a transição de um grupo para o outro ou apenas a incorporação de alguns aspectos. Segundo Revell (2016), isso pode ser utilizado para demonstrar quem faz parte do grupo, quem é excluído (REVELL, 2016, p. 107) e, também, quem se exclui. Quem não entende o significado de cada detalhe não faz parte da comunidade, o que cria e mantém limites (REVELL, 2016, p. 107).

A cor, a forma e a decoração, por exemplo, podem ser selecionadas para definir um grupo. Muitas vezes, o modo de se vestir pode revelar uma forma de disciplina institucional ou, de maneira mais informal, pode compreender uma série de assuntos, que não são mencionados, mas demonstram o que é apropriado. Nesse sentido, a vestimenta também é uma forma de comunicação. Portanto, a mudança de vestuário faz parte de um processo de transformação cultural, que é uma pequena parte de uma série de alterações. De acordo com as características de vestimenta que Revell (2016) cita em sua obra, a túnica e o manto que Regina usa no altar parecem ser do costume das mulheres romanas. Contudo, entre os dois grupos, poderiam ter costumes em comum (REVELL, 2016, p. 107). A esse respeito, Allanson-Jones (2005) sugere, em relação à identidade, que muitas dessas mulheres poderiam ter se sentido deslocadas, confusas e psicologicamente doentes, de modo que o suicídio poderia ter acontecido (ALLANSON-JONES, 2005, p. 76).

\section{Conclusão}

Nessa perspectiva, pode-se concluir que, através das rebeliões provinciais relatadas pelos antigos escritores, do exemplo das construções redondas em prédios romanos dado anteriormente, assim como dos exemplos de heterogeneidade cultural observada pelos 
epitáfios, os resultados da migração e consequente contato são evidenciados de forma escrita e material, sendo esses vestígios vetores para demonstrarem os processos socioculturais que envolveram a questão de uma continuidade cultural, mas que nesse percurso possa ter sofrido mudanças, variedades, choques, traumas e outras formas de interação.

Para tribos bretãs, que já haviam passado por diversas revoltas contra a invasão romana, assim como a de Carataco e Boudica, a conformação com a cultura estrangeira poderia ter sido uma forma de trégua. Todavia, a adequação aos modos de vida e a regras estranhas poderiam acabar resultando em outros tipos de conflitos, assim como o psicológico, ou interagir quando a situação fosse mais ou menos equilibrada. $\mathrm{O}$ contato de distintos grupos com diferentes sistemas socioculturais é um fenômeno inerente ao ser humano, o qual tem ocorrido desde os primórdios de sua existência até os dias de hoje, numa "sociedade globalizada de rede", tanto do modo mais pacífico como do mais violento.

Dificilmente já existiu uma sociedade com total isolamento. Contudo, a dificuldade de se estudar esses acontecimentos de migração está no fato de que eles apenas são vistos a partir de seu resultado, ou seja, pelo término de um fenômeno que é muito mais complexo e que envolve a interação entre as sociedades (CUCHE, 1999). Nesse aspecto, a multiplicidade de tipos de fontes, tais como a escrita e a material, é essencial para a via de acesso à compreensão desse processo.

\section{BRITANNIA: VIOLENCE, POWER AND CONTACT}

Abstract: This article aims to demonstrate - through written sources of ancient authors such as the works of Tacitus (Annals and Agricola) as well as the work of Cassius Dio (Roman History) - how the violence of occupation of the province of Britannia was placed by these authors, since the imposition of Roman power brought consequences for the life of the native community of that region. The rebellions highlighted are those of Carataco and, especially, of Boudica, giving greater emphasis to the issue of rape of the daughters of the Iceni queen. This passage corroborates with commentaries on the point of view of current scholars on this subject and the question about why these ancient writers presented such a heinous act in their works. The implications of the process of Roman invasion 
and the provincial take came from later results, which are demonstrated in this work through the material culture represented by epitaphs, through which the life of the native women, who have joined the Romans, which formed a cultural heterogeneity, are demonstrated.

Keywords: Britannia. Rebellion. Violence. Power. Contact.

\section{Notas}

${ }^{1}$ Desde o período de Heródoto, a concepção grega do "outro" foi articulada de acordo com o conceito de "bárbaro". Inicialmente associado aos Persas, o termo "bárbaro" conotava para Heródoto e outros gregos uma inclinação à subserviência e à tirania. Para os escritores romanos que, subsequentemente, se apropriaram do conceito em suas narrativas, acabaram dando uma ideologia política ao império. Dessa maneira, o termo "Barbarismo", para esses últimos, implicava uma condição inferior, assim como uma natureza inferior (MCCOSKEY, 2005, p. 60-61; SAAVEDRA, 1999, p. 60).

${ }^{2}$ Essa questão implica o debate sobre o termo Romanização, conceito que foi criado no início do século XX, pelo inglês Francis Haverfield, para explicar o crescimento do Império Romano. Ele foi um dos fundadores da Arqueologia romano-britânica e elaborou o conceito de Romanização a partir de seus estudos e escavações em território britânico, junto com as ideias do alemão Mommsen (FUNARI; GARRAFFONI, 2004, p. 11). Funari e Garraffoni (2004) salientam que Hingley e demais estudiosos que seguem uma perspectiva pós-colonial enfatizam que a ideia de Romanização estava vinculada à visão inglesa imperialista. Para Hingley, é impossível compreender o conceito de Romanização sem recorrer ao momento histórico que fora criado, ou seja, um período em que ingleses acreditavam que o progresso e a civilização somente poderiam chegar sob liderança imperial, como se houvesse uma transposição de valores ingleses para o passado romano. Acreditava-se que os ingleses herdaram dos romanos, via descendência bretã, a missão de civilizar povos bárbaros no mundo (FUNARI; GARRAFFONI, 2004, p. 11-12). O termo Romanização estava vinculado ao conceito de aculturação, em que o prefixo "a" vem do latim $a d$, que indica um movimento de aproximação, e foi criado em 1880, por J. W. Powell, antropólogo americano que via a aculturação como uma ação de mão única (CUCHE, 1999) em que, diante de uma visão evolucionista, o mais forte sempre prevaleceria sobre o mais fraco, ou seja, pensava-se que o colonizador subjugaria o colonizado. Apenas nos anos 1950, o antropólogo francês Roger Bastide, discípulo de Franz Boas (geógrafo e antropólogo alemão, que atuava 
nos EUA), dedicou-se a trabalhos sobre a cultura afro-brasileira e introduziu na França pesquisas sobre aculturação. Em sua análise, levou em conta tanto o grupo que dá quanto o grupo que recebe, posto que, para o estudioso, não havia uma cultura unicamente "doadora" nem uma cultura unicamente "receptora" propriamente dita. A aculturação não se produz jamais em mão única. Toda cultura é um processo permanente de construção (CUCHE, 1999).

${ }^{3}$ Roman Inscriptions of Britain.

${ }^{4}$ Disponível em: <https://romaninscriptionsofbritain.org/inscriptions/688>. Acesso em: 11 abril 2017.

${ }^{5}$ Disponível em: 〈https://romaninscriptionsofbritain.org/inscriptions/688>. Acesso em: 11 abril 2017.

${ }^{6}$ Disponível em: <https://www.yorkmuseumstrust.org.uk/collections/search/ item/?id=1089>. Acesso em: 14 jul. 2017.

${ }^{7}$ Disponível em: 〈https://romaninscriptionsofbritain.org/inscriptions/688>. Acesso em: 11 abril 2017.

${ }^{8}$ Tradução nossa, inglês-português, 2017.

9 Disponível em: <https://www.yorkmuseumstrust.org.uk/collections/search/ item/?id=1089\&search_query=bGltaXQ9MTYmc2VhcmNoX3RleHQ9SnVsa WErVmVsdmEmR3MINUJvcGVyYXRvciU1RD01M0U1M0QmR3MINUJ2Y Wx1ZSU1RD0mR2U1NUJvcGVyYXRvciU1RD01M0M1M0QmR2U1NUJ2Y Wx1ZSU1RD0mRk49>. Acesso em: 29 jul. 2017.

${ }^{10}$ Disponível em: < http://www.nu-digitalheritage.com/CatalogueRetrieve. aspx?ProductID $=9038865 \& A=$ SearchResult $\&$ SearchID $=395928 \&$ ObjectID $=$ 9038865\&ObjectType=27>. Acesso em: 14 jul. 2017.

${ }^{11}$ Disponível em: 〈http://romaninscriptionsofbritain.org/inscriptions/1065〉. Acesso em: 2 nov. 2015.

${ }^{12}$ Disponível em: 〈http://romaninscriptionsofbritain.org/inscriptions/1065〉. Acesso em: 2 nov. 2015.

${ }^{13}$ Tradução P. P. A. Funari, 2017, que entende, com RIB 1065, que Regina liberta está no ablativo, no lugar do usual dativo.

${ }^{14}$ Disponível em: <http://www.nu-digitalheritage.com/CatalogueRetrieve. aspx?ProductID=9038865>. Acesso em: 31 jul. 2017. 


\section{Referências}

ALDHOUSE-GREEN, M. Boudica Britannia. London: Pearson Longman, 2006. ALLASON-JONES, L. Women in Roman Britain. York: Council for British Archaeology, 2005.

. Women in Roman Britain. In: James, L. S.; Dillon, S. (Ed.). A companion to women in the Ancient world. Oxford: Blackwell Publishing, 2012.

BÉLO, T. P. Estudo tecnológico e das cadeias operatórias da cultura material lítica e cerâmica, coletada nos anos de 1995, 1996 e 2000, no sítio Água Limpa, município de Monte Alto, SP. 2007. 190 f. Dissertação (Mestrado em Arqueologia)-Museu de Arqueologia e Etnologia da Universidade de São Paulo, São Paulo, 2007.

Boudica e as facetas femininas ao longo do tempo: nacionalismo, feminismo, memória e poder. 2014. 261 f. Tese (Doutorado em História)-Departamento de História, Instituto de Filosofia e Ciências Humanas da Universidade Estadual de Campinas, Campinas, 2014.

BOURDIEU, P. Outline of a theory of practice. Cambridge: Cambridge University Press, 1977.

CAESAR, C. I. De bello Gallico. Texto latino revisado por Manuel A. Gámez. Barcelona: Bosh, 1988.

CAHILL, A. J. Rethinking rape. Ithaca; London: Cornell University Press, 2001.

CASSIUS DIO. Roman History. Translated by Ernest Cary. London: W. Heinemann, 1914-1927. 9 v.

CUCHE, D. A noção de cultura nas ciências sociais. Bauru: Edusc, 1999.

DAVIES, J.; ROBINSON, B. Boudica: her life, times and legacy. Cromer: Poppyland Publishing, 2009.

DOBRES, M. A.; ROBB, J. E. Agency in Archaeology. Oxford: Blackwell, 2000.

DWORKIN, A. Pornography: men possessing women. New York: E. P. Dutton, 1989.

FIELDS, N. Boudicca's rebellion AD 60-61: the Britons rise up against Rome. Oxford: Osprey Publishing, 2011.

FUNARI, P. P. A.; GARRAFONI, R. S. História Antiga na Sala de Aula. Textos Didáticos, Campinas, n. 51, jul. 2004. ISSN 1676-7055.

GARCIA, M. L. Las mujeres en la Gallaecia antigua. Gallaecia, Corunha, n. 16, p. 159-172, 1997. 
HINGLEY, R. Resistance and domination: social change in Roman Britain. In: MATTINGLY D. (Ed.). Dialogues in Roman Imperialism: power, discourse and discrepant experience in the Roman empire. Cambridge: Cambridge University Press, 1997. p. 81-100. (Journal of Roman Archaeology Supplementary Series, v. 23).

. O imperialismo romano: novas perspectivas a partir da Bretanha. Tradução de Luciano César Garcia Pinto. São Paulo: Annablume, 2010.

HINGLEY, R.; UNWIN, C. Boudica: Iron Age warrior queen. London: Hambledon Continuum, 2005.

HODDER, I. Symbols in action: ethnoarchaeological studies of material culture. Cambridge: Cambridge University Press, 2009.

JOHNSON, M. H. Conceptions of agency in archaeological interpretation. Journal of Anthropological Archaeology, Amsterdam, v. 8, n. 2, p. 189-211, 1989.

JOHNSON, M. Boudicca. London: Bristol Classical Press, 2012.

JONES, S. The archaeology of ethnicity. London: Routledge, 1997.

MATTINGLY, D. Being Roman: expressing identity in a provincial setting. Journal of Roman Archaeology, Cambridge, v. 17, p. 5-25, 2004.

MCCOSKEY, D. E. Gender at the crossroads of empire: locating women in Strabo's Geography. In: DUECK, D.; LINDSAY, H.; POTHECARY, S. (Ed.). Strabo's cultural geography: The Making of a Kolossourgia. Cambridge: Cambridge University Press, 2005. p. 56-72.

MORGAN, R. Going too far: the personal chronicle of a feminist. New York: Random House, 1977.

PINTO, R. Duas rainhas, um príncipe e um eunuco: gênero, sexualidade e as ideologias do masculino e do feminino nos estudos sobre a Bretanha Romana. 2011. 254 f. Tese (Doutorado)-Instituto de Filosofia e Ciências Humanas da Universidade Estadual de Campinas, São Paulo, 2011.

REVELL, L. Ways of being roman: discourses of identity in the roman west. Oxford; Philadelphia: Oxbow Books, 2016.

SAAVEDRA, T. Women as focalizers of barbarism in conquest texts. Echos $d u$ Monde Classique: Cassical Views, Canada, v. 43, n.s. 18, p. 59-77, 1999.

SALWAY, P. The Oxford illustrated history of Roman Britain. Oxford: OUP, 1993. SEALEY, P. R. The Boudican revolt against Rome. Oxford: Shire Publications, 1997. 
STRABO. The Geography. Translated by H. L. Jones. Loeb Classical Library: Harvard University Press, 1917-1932. 8 v. Disponível em: <http://penelope. uchicago.edu/Thayer/e/roman/texts/strabo/home.html>. Acesso em: 14 jul. 2017. TACITUS, P. C. Agricola. Tradução de W. Peterson. Londres: William Hinemann LTC; Cambrigde, MA: Harvard University Press, 1914.

. The Annals and The Histories. Translated by A. J. Church and W. J. Brodribb. Great Britain: Penguin Classics, 1952.

. The Germania. Translated by Alfred John Church and William Jackson Brodribb. London; New York: The Macmillan Company, 1877.

WHITTAKER, C. R. Frontiers of the Roman Empire: a social and economic study. London: Johns Hopkins University, 1994.

Recebido em: 26/11/2017

Aprovado em: 30/01/2018 
